\title{
Clinical Characteristics and Outcome of Obstetric Patients Who Required Mechanical Ventilation in a Tertiary Care Hospital in North Kerala.
}

\author{
Dr Smitha Sreenivas.K ${ }^{1}$, Dr Naseema Beevi.A²,Dr Uma Devi $\mathrm{N}^{3}$ \\ ${ }^{I}$ (Obstetrics \& Gynaecology, Government Medical College/Kozhikode, India) \\ ${ }^{2}$ (Obstetrics \& Gynaecology, Government Medical College/Kozhikode, India) \\ ${ }_{3}^{3}$ (Obstetrics \& Gynaecology, Government Medical College/Kozhikode, India)
}

\begin{abstract}
:
Objectives: To describe the clinical characteristics of obstetric patients requiring mechanical ventilation in a tertiary referral hospital and their maternal and perinatal outcome, in order to identify their risk factors and clinical outcome and determine adverse prognostic factors in these patients.

Study design: A prospective study was conducted in the Department of Obstetrics and Gynaecology, Government Medical College,Kozhikode of all pregnant women upto 6 weeks postpartum from January 1,2011 to December 31,2013 and subsequently required mechanical ventilation.Data was recorded in a predesigned proforma and was analysed and frequency and percentages were calculated.

Results: In the three year period 75 obstetric patients required mechanical ventilation.Majority were between 20-35 years(88\%)and were primipara(53.3\%).80\% were admitted in the antepartum period and most were in the gestational age of 30-36 weeks(41.3\%).Hypertensive disorder is the important antepartum complication(29.3\%). Postpartum hemorrhage was the important cause (45.3\%) of ICU admission. 49.3\% required mechanical ventilation for less than 24 hours and multiorgan failure was the important complication encountered(13.3\%).

Conclusions: Providing optimal prenatal care and improving the management of hemorrhagic complications and hypertensive disease can improve the morbidity and mortality of critically ill obstetric patients requiring mechanical ventilation.
\end{abstract}

Keywords: critical illness, high risk pregnancy, hypertension, maternal death, mechanical ventilation

\section{Introduction}

Pregnancy,delivery and puerperium can have catastrophic complications necessitating ICU admission,although these patients are young and healthy in general.The critically ill pregnant patients present a challenge to the physician due to their unique physiology and the specific medical disorders that occur during pregnancy and peripartum period.The physiological changes that occur in the pregnant state in several systems including the cardiovascular, respiratory, renal,hematologic and endocrine systems, stress the reserve of the body and may compromise responses needed to combat disease state. The critical illness can be due to pregnancy per se or can be due to a concurrent medical illness.Hypertensive disorders of pregnancy,hemorrhage and sepsis are the leading causes of maternal morbidity and ICU admissions in Asia ${ }^{1}$.Management of critically ill pregnant lady requires the cooperation of obstetrician,intensivist and anaesthetist.

Mechanical ventilation has revolutionized the management of critically ill patients with pulmonary dysfunction.It was introduced in the latter half of the twentieth century.It is essential for the support of those patients whose respiratory dysfunction threatens homeostasis and life ${ }^{10}$. Most aspects of mechanical ventilation are identical for pregnant and nonpregnant women ${ }^{9}$.It has two simple functions, to give an adequate supply of oxygen and eliminate carbondioxide.The indications for instituting mechanical ventilation are based on clinical assessment.Tachypnoea,tachycardia,alae flaring,use of accessory muscles of respiration,sweating and a thorough understanding of the underlying pathology constitute enough evidence for intubation and ventilation.Physiological changes of pregnancy and concerns for fetal wellbeing complicate the use of mechanical ventilation.Maternal morbidity and mortality are significantly elevated in obstetric patients requiring mechanical ventilation ${ }^{7}$.Fetal mortality is also high when critical care is required.Early gestational age,severe maternal illness,maternal shock and the absence of prenatal care are associated with fetal mortality ${ }^{9}$.Upon resolution of underlying pathology mechanical ventilation may be withdrawn ${ }^{10}$.Successful maternal and neonatal outcomes are largely dependent on a multidisciplinary approach to management requiring input from critical care personnel,obstetricians, anaesthetists, neonatologists and nursing personnel.

Increased surveillance in the peripartum period in a critical care facility allows earlier detection of maternal compromise and detailed management ${ }^{8}$. Analysis of these critical care obstetric patients help to improve future pregnancy outcomes. 


\section{Materials And Methods}

We included in our study pregnant women upto 6 weeks postpartum admitted in our Department from January 1,2011 to December 31,2013 and who subsequently required mechanical ventilation.Data collected include maternal age,parity,gestational age,booking status,presence of antepartum complications,mode of delivery,requirement of blood and blood products and hysterectomy,indication of ICU admission,duration of ventilation,length of hospital stay,complications encountered in ICU and fetal outcome and were recorded in a predesigned proforma.Data was analysed and frequency and percentages were calculated.

\section{Results}

A total of 75 obstetric patients required mechanical ventilation during the three year period.Majority of the patients belonged to the age group of 20-35 years ,66(88\%) .Only 4(5.3\%) were below 20 years and $5(6.67 \%)$ were above 35 years.40(53.3\%)were primipara and 33(44\%) were multipara. 60(80\%) were admitted in the antepartum period. $54 \operatorname{cases}(72 \%)$ were referred from another institution.Most of the patients were in the gestational age of 30-36 weeks,30cases(40\%). Only 15(20\%)were in the postpartum period..Caesarean section was an important risk factor amounting to $41(54.67 \%)$ patients.20 cases $(26.67 \%)$ had undergone hysterectomy ,may be due to high incidence of postpartum hemorrhage in our study. 8 cases required relaparotomy due to intraperitoneal hemorrhage. There were 51 live births of which $6(11.76 \%)$ ended in neonatal death,may be related to early gestational age and severe maternal illness.

Hypertensive disorder was the most important antepartum risk factor, which included preeclampsia 5(6.67\%),eclampsia 4(5.3\%), gestational hypertension 4(5.3\%) and HELLP syndrome in 4(5.3\%) and both eclampsia and HELLP syndrome in 5(6.67\%).Other obstetric complications included placenta accreta present in 7( 9.3\%), abruption in 5(6.67\%), multiple pregnancy in 4(5.33\%), GDM in 2(2.67\%) and AFLP in 2(2.67\%).

Preexisting medical complications included heart disease in 3 cases $(4 \%)$.Chronic hypertension,pregestational diabetes,sickle cell disease ,SLE and rheumatoid arthritis contribute in $1.3 \%$ each. $32 \%$ required transfusion of more than 10 blood and blood products which can be due to more cases of postpartum hemorrhage.

The most important obstetric complication necessitating ICU admission was postpartum hemorrhage22(29.3\%). Postpartum hemorrhage with disseminated intravascular coagulation was the cause in 12 cases(16\%).Hypertensive disorders followed closely including eclampsia with HELLP Syndrome in 5(6.67\%) and HELLP syndrome in 3(4\%). Posterior reversible encephalopathy syndrome was present in $3(4 \%)$.Amniotic fluid embolism was responsible in 3(4\%) and peripartum cardiomyopathy and inversion contributed in $1.3 \%$ each.

Majority required mechanical ventilation for less than 24 hours,37(49.3\%).Only 9 cases(12\%) required ventilation for 5 days and more. 30 cases(40\%)required hospital stay for 10 to 19 days and only 6(8\%) required hospital stay for more than a month.

Multiorgan failure was the most important complication encountered while on mechanical ventilation,seen in 10(13.3\%).Pulmonary edema developed in 4(5.3\%) and renal failure and seizures were found in 3 cases each (4\%).Ventilator associated pneumonia developed in 2(2.67\%).Hepatic failure,cardiac arrhythmias,deep vein thrombosis and burst abdomen complicated in 1 case each(1.3\%)

There were 26 maternal deaths in patients who required mechanical ventilation.Postpartum hemorrhage(30.76\%) ,sepsis(23.08\%) and hypertensive disorders(19.02\%) were the important causes of maternal mortality.Other causes were pulmonary embolism(7.69\%), intracranial hemorrhage $(7.69 \%)$, amniotic fluid embolism $(3.85 \%)$, acute fatty liver of pregnancy $(3.85 \%)$ and heart disease $(3.85 \%)$.

\section{Discussion}

Maternal and perinatal morbidity and mortality are significantly elevated in obstetric patients requiring mechanical ventilation ${ }^{7}$ possibly due to severity of maternal illness and early gestational age.A critically ill pregnant woman poses major challenges to physicians. The serious illness that complicate pregnancy may be unique to pregnancy,but other medical conditions that affect nonpregnant women also may complicate pregnancy.Early identification of critical illness is essential to provide aggressive support and resuscitation including ventilatory support and reduce maternal mortality.Majority of the patients belonged to 20 to 35 years age group $(88 \%)$ similar to the study of Shaikh.S et al ${ }^{1}$.In our study $53.3 \%$ were primipara, which contradicts with the same study ${ }^{1} .80 \%$ were admitted antepartum similar to $78 \%$ in study by Shaikh.s et al ${ }^{1}$ and German A Monsalve ${ }^{6}$.Most were in the gestational age between 30 and 36 weeks $(40 \%)$, similar to study by Turkan $\mathrm{Togal}^{3} .72 \%$ were transferred from another institution similar to study by Helen R Barrett ${ }^{8}$. Hypertensive disorders were found to be the most important antepartum risk factor $(29.3 \%)$, similar to study by Vivek $\mathrm{Kumar}^{4}$.Other antepartum complications included placenta accreta $9.3 \%$,abruption $6.67 \%$,multiple pregnancy $5.33 \%$,AFLP $2.67 \%$ and gestational diabetes in $2.67 \%$. The most important preexisting medical complication 
was heart disease, in 3 cases(4\%).32\% required transfusion of more than 10 units of blood and blood products probably due to the high incidence of postpartum hemorrhage.

The most common mode of delivery was caesarean section $54.67 \%$ similar to study by Shaikh.S et al ${ }^{1}$ where it was $49.4 \%$.Obstetric hysterectomy was required in $26.67 \%$ since postpartum hemorrhage was the most important cause of ICU admission. Still births were 32\% and of the 51 live births, $11.76 \%$ ended in neonatal death which was higher than the study of Jose Rojas Suarez ${ }^{7}$.

The most common obstetric cause of ICU admission was postpartum hemorrhage 34(45.3\%) of which 12 cases were complicated with disseminated intravascular coagulation which is similar to study by Jose Rojas Suarez $^{7}$ and Helen R Barrett ${ }^{8}$ but contradicts the study by Tuncer Simsek ${ }^{4}$ where hypertensive disorder was the most common cause.Other causes were hypertensive disorders including HELLP syndrome in $4 \%$ and eclampsia with HELLP syndrome in 6.67\%,amniotic fluid embolism in 4\%,Posterior reversible leukoencephalopathy syndrome in $4 \%$,peripartum cardiomyopathy in $1.3 \%$ and inversion uterus in $1.3 \%$.Sepsis was the most important nonobstetric cause of ICU admission(8\%) similar to study by Shaikh.S et al ${ }^{1}$,followed by pulmonary edema in $5.33 \%$ and pulmonary embolism in 5.33\%.Intracranial hemorrhage was present in $2.67 \%$.There was only one case each of anaphylaxis and delayed recovery from general anaesthesia.

Majority required mechanical ventilation for less than 24 hours,37(49.3\%) where as the mean duration was 3 days in a study by Jose Rojas Suarez ${ }^{7}$.Only 9 cases(12\%) required for 5 days and more.30 cases(40\%)required hospital stay for 10 to 19 days and only 6 cases $(8 \%)$ required hospital stay for more than 30 days.

Multiorgan failure was the most important complication encountered while on mechanical ventilation in 10(13.3\%).Pulmonary edema developed in 4(5.3\%) and renal failure and seizures were found in 3 cases each (4\%) and ventilator associated pneumonia in $2.67 \%$. Hepatic failure,cardiac arrhythmias,deep vein thrombosis and burst abdomen complicated in 1 case each $(1.3 \%)$

There were 26 maternal deaths in patients who required mechanical ventilation(34.67\%) similar to study by Jose Rojas Suarez ${ }^{7}$.Postpartum hemorrhage(30.76\%),sepsis(23.08\%) and hypertensive disorders(19.02\%) were the important causes of maternal mortality.Other causes were pulmonary embolism (7.69\%),intracranial hemorrhage(7.69\%),amniotic fluid embolism(3.85\%), acute fatty liver of pregnancy (3.85\%) and heart disease $(3.85 \%)$.

TABLES

Table 1

\begin{tabular}{|c|c|c|}
\hline Characteristics & Number & Percentage \\
\hline \multicolumn{3}{|l|}{ Age (years) } \\
\hline$<20$ & 4 & 5.3 \\
\hline $20-35$ & 66 & 88 \\
\hline$>35$ & 5 & 6.67 \\
\hline \multicolumn{3}{|l|}{ Parity } \\
\hline Primipara & 40 & 53.3 \\
\hline Multipara & 33 & 44 \\
\hline Grandmultipara & 2 & 2.67 \\
\hline \multicolumn{3}{|l|}{ Time of admission } \\
\hline Antepartum & 60 & 80 \\
\hline Postpartum & 15 & 20 \\
\hline \multicolumn{3}{|l|}{ Mode of admission } \\
\hline Referred & 54 & 72 \\
\hline Booked & 21 & 28 \\
\hline \multicolumn{3}{|l|}{ Gestational age(weeks) } \\
\hline$<30$ & 5 & 6.67 \\
\hline $30-36$ & 30 & 40 \\
\hline $37-41$ & 25 & 33.3 \\
\hline Postpartum upto 42 days & 15 & 20 \\
\hline
\end{tabular}

Demographic characteristics of patients

Table 2

Presence of antepartum complications 


\begin{tabular}{|l|l|l|}
\hline Complications & Number & Percentage \\
\hline Obstetric complications & & \\
\hline Placenta accreta & 7 & 9.3 \\
\hline Preeclampsia & 5 & 6.67 \\
\hline Eclampsia +HELLP & 5 & 6.67 \\
\hline HELLP syndrome & 4 & 5.3 \\
\hline Eclampsia & 4 & 5.3 \\
\hline Gestational hypertension & 4 & 5.3 \\
\hline Abruption & 5 & 6.67 \\
\hline Multiple pregnancy & 4 & 5.3 \\
\hline AFLP & 2 & 2.67 \\
\hline Gestational diabetes & 2 & 2.67 \\
\hline Medical complications & & \\
\hline Heart disease & 3 & 4 \\
\hline SLE & 1 & 1.3 \\
\hline Chronic hypertension & 1 & 1.3 \\
\hline Pregestational diabetes & 1 & 1.3 \\
\hline Sickle cell disease & 1 & 1.3 \\
\hline Rheumatoid arthritis & 1 & 1.3 \\
\hline
\end{tabular}

Table 3

\begin{tabular}{|l|l|l|}
\hline $\begin{array}{l}\text { Number of units of blood and blood } \\
\text { products }\end{array}$ & & \\
\hline$<5$ & 19 & 25.3 \\
\hline $5-10$ & 16 & 21.3 \\
\hline$>10$ & 24 & 32 \\
\hline Nil & 16 & 21.3 \\
\hline
\end{tabular}

Number of blood and blood products

Table 4

Cause of ICU admission

\begin{tabular}{|l|l|l|}
\hline Obstetric cause & & \\
\hline PPH & 22 & 29.3 \\
\hline PPH,DIC & 12 & 16 \\
\hline Eclampsia +HELLP & 5 & 6.67 \\
\hline HELLP Syndrome & 3 & 4 \\
\hline Amniotic fluid embolism reversible encephalopathy & 3 & 4 \\
\hline $\begin{array}{l}\text { Posterior } \\
\text { syndrome }\end{array}$ & 3 & 4 \\
\hline Inversion uterus & 1 & 1.3 \\
\hline Peripartum cardiomyopathy & 1 & 1.3 \\
\hline Nonobstetric cause & & \\
\hline Sepsis & 6 & 8 \\
\hline Pulmonary edema & 4 & 5.33 \\
\hline Pulmonary embolism & 4 & 5.33 \\
\hline Status eclampticus & 3 & 4 \\
\hline Heart disease & 3 & 4 \\
\hline Hepatic failure & 2 & 2.67 \\
\hline Intracranial hemorrhage & 2 & 2.67 \\
\hline Anaphylaxis & 1 & 1.3 \\
\hline Delayed recovery after general anaesthesia & 1 & 1.3 \\
\hline
\end{tabular}

Table 5

\begin{tabular}{|l|l|l|}
\hline Duration of mechanical ventilation (days) & & \\
\hline$<1$ & 37 & 49.3 \\
\hline $1-2$ & 23 & 30.67 \\
\hline $3-4$ & 6 & 8 \\
\hline$\geq 5$ & 9 & 12 \\
\hline Duration of hospital stay(days) & & \\
\hline$<10$ & 16 & 21.3 \\
\hline $10-19$ & 30 & 40 \\
\hline $20-30$ & 23 & 30.67 \\
\hline$>30$ & 6 & 8 \\
\hline
\end{tabular}

Duration of mechanical ventilation and hospital stay 
Table 6

\begin{tabular}{|l|l|l|}
\hline Complications & & \\
\hline Multiorgan failure & 10 & 13.3 \\
\hline Pulmonary edema & 4 & 5.3 \\
\hline Renal failure & 3 & 4 \\
\hline Seizures & 3 & 4 \\
\hline Ventilator associated pneumonia & 2 & 2.67 \\
\hline Hepatic failure & 1 & 1.3 \\
\hline Cardiac arrhythmias & 1 & 1.3 \\
\hline Burst abdomen & 1 & 1.3 \\
\hline DVT & 1 & 1.3 \\
\hline
\end{tabular}

Complications encountered while on mechanical ventilation

Table 7

\begin{tabular}{|l|l|l|}
\hline Diagnoses & Number of patients & Percentage of maternal deaths (\%) \\
\hline Postpartum hemorrhage & 8 & 30.76 \\
\hline Sepsis & 6 & 23.08 \\
\hline Hypertensive disorders & 5 & 19.02 \\
\hline Pulmonary embolism & 2 & 7.69 \\
\hline Intracranial hemorrhage & 2 & 7.69 \\
\hline Amniotic fluid embolism & 1 & 3.85 \\
\hline Acute fatty liver of pregnancy & 1 & 3.85 \\
\hline Heart disease & 1 & 3.85 \\
\hline
\end{tabular}

Maternal mortality -26 cases $(34.67 \%)$

\section{Conclusion}

A close follow up of high risk patients and an optimal stabilization of their condition before intervention are well known to improve the outcome of these patients and decrease the morbidity and mortality.The problems faced by the critically ill parturients including mechanical ventilation may be reduced by providing optimal prenatal care,improving the management of hypertensive disease during pregnancy and reducing the incidence of hemorrhagic complications.

\section{Acknowledgements}

We acknowledge all the staff and residents involved in the care of these patients.

\section{References}

[1]. Shaikh S, Shaikh NB, Abassi R, Balouch R. Obstetric admission to the intensive care unit:A one year review.Medical channel.2013;19:59-63

[2]. Kilpatrick SJ, Matthay MA. Obstetric patients requiring critical care:A five year review.Chest.1992;101:1407-12

[3]. Togal T, Yucel N, Gedik E, Gulhas N, Toprak HI, Ercoy O. Obstetric admissions to the intensive care unit in a tertiary referral hospital.Journal of critical care.2010;25:628-33

[4]. Kumar V. Critical illness in pregnancy.Medicine update.2012;22:700-10

[5]. Simsek T, Eyigor C, Uyar M, Karaman S, Moral AR. Retrospective review of critically ill obstetrical patients:a decade's experience.Turk J Med Sci.2011;41:1059-64

[6]. Monsalve GA et al. Maternal critical care:outcomes and patient characteristics in a combined obstetric high dependency unit in Medellin,Colombia.Rev.Col.Anest.2011;39:190-205

[7]. Suarez JR, Duenas C, Paternina A, Miranda J, Castillo E, Bourjeily G. Clinical characteristics and outcomes of obstetric patients requiring mechanical ventilation in Colombia.Chest.2012;10:142

[8]. Barrett HL et al. A fifteen year retrospective review of obstetric patients requiring critical care.Obstet Med.2012;5:166-70

[9]. Clardy PF, Reardon CC. Critical illness during pregnancy and the peripartum period.UpToDate 2014

[10]. Muckart DJJ.Ventilation and the critically ill parturient. Best Pract Res Clin Obstet Gynaecol.2011;15:545-56 